\title{
PRESENCIA DE LAS ESCUELAS Y LOS COLEGIOS \\ PARROQUIALES CATÓLICOS EN LA EDUCACIÓN PERUANA
}

César Cortez Mondragón ${ }^{1}$

$\mathrm{T}$

odavía no se ha investigado, en detalle, sobre la importancia de las Escuelas Parroquiales en el Perú. Algunos trabajos de investigación están mayormente referidos a los aspectos estadísticos dentro de la Iglesia. Si se le menciona, en otros casos, es para integrarlas como parte de las instituciones religiosas de ayuda y referencia social que tiene la Iglesia. Sin embargo, su labor ha sido tan fundamental en el desarrollo de la educación peruana, tanto que ha representado, y representa, para la Iglesia como para el estado, a una institución que promueve integración y desarrollo educativo entre las familias de comunidades locales que buscan la buena formación de sus hijos .

Hemos encontrado que la Escuela Parroquial es una de las pocas instituciones que ha mantenido su estatus de labor social dentro del desarrollo de la formación de la identidad en el país. Es aquella que ha podido mantener la misma esencia a pesar del tiempo y los cambios que ha tenido nuestro país. Por eso nos hace pensar que la escuela parroquial es digna de

1 Profesor del Centro de Servicios Educativos (CESED) de la Facultad de Ciencias de la Educación de la Universidad Católica Sedes Sapientiae. 
estudiarse y tratar de sacar de ella los valores que pueden ayudar al desarrollo de la educación, dentro de la cooperación y la forma de evangelización que realiza la Iglesia.

El estudio realizado está dispuesto primero con una visión de lo que significa la Parroquia como institución de la Iglesia Católica, luego hacemos ver sus inicios en la Europa medieval y la manera cómo llegó a nuestro país con el advenimiento de los europeos. Los capítulos posteriores están referidos al desarrollo de esta institución educativa en las diferentes etapas de la historia del Perú (Colonia, Emancipación, República de los siglos XIX y xx). A manera de conclusión se ha expuesto el reglamento que tuvieron los Colegios Parroquiales y lo que representan actualmente para la educación peruana.

Pensamos que el trabajo es modesto, pero puede ser el inicio para conocer una Institución que sigue siendo una opción para los pobres mediante de la labor formativa de la Iglesia Católica. Queremos que el presente trabajo despierte la inquietud para los estudiosos de la educación peruana. Los detalles de los análisis son producto de la experiencia, porque hemos vivido profesionalmente más de tres décadas dentro de esta clase de colegios y sabemos de su calidad educativa en la enseñanza y el aprendizaje.

Por último sabemos que hoy como nunca la experiencia de los cambios motiva nuevas visiones de la cultura, hacia ello va nuestra razón de hacer el presente trabajo: divulgar lo que se tiene para aprovecharlo.

\section{LA PARROQUIA DE HOY}

\section{El párroco y la parroquia}

A menudo identificamos a la Parroquia de nuestro barrio o nuestro distrito, como el lugar donde acudimos los domingos para oír misa o pedimos la 
administración de algún sacramento. Identificamos también con el trabajo de apostolado que ciertos religiosos realizan con sus parroquianos para conseguir la salvación de sus almas. Este análisis se debe cambiar para comprender, a esta institución celular de la Iglesia, como uno de los ejes comunitarios, dentro de las cuales adquirimos una formación ciudadana, religiosa, moral, social, educativa, hasta política.

La Parroquia deriva de la terminología griega parochus que significa 'habitar' o bien 'ofrecer y administrar' (cf. Birgillist 1921). El otro origen es latino (parrochia). En ambos casos se entiende como la jurisdicción territorial que algunos religiosos atienden espiritualmente. El párroco sería una persona que es elegida por el Obispo para que asista y viva en un lugar asignado, con el fin de poder administrar a sus fieles el encargo espiritual de sus almas.

Una de las frecuente confusiones se da en el uso de la terminología de «Párroco» con el de «Cura». La razón puede ser que ambos viven en la misma institución y se encargan de cuidar el aspecto espiritual por mandato del Obispo. Sin embargo, el cura es el encargado, en virtud del oficio que tiene, del cuidado, instrucción y doctrina espiritual de una feligresía. Significa el que cuida, como especie de pastor que tiene ciertas obligaciones personales con respecto a los que forman una curia (también territorio bajo guía y dirección espiritual del cura). Indicamos esto porque tanto en uno como en el otro los Obispos depositan la confianza de pastores, guardianes y protectores de los fieles, pero en el Párroco la labor espiritual desborda la ayuda religiosa-espiritual para complementar con la labor educativa y asistencial.

Aunque hay requisitos para que se establezca la Parroquia dentro de la Iglesia, algunas de ellas son indispensables y no pueden faltar (cf. Donas 1869), por ejemplo: 
- Que exista una persona (religioso) que tenga la potestad de administrar los sacramentos de la iglesia.

- Que exista, para la administración de la Iglesia, una determinada área geográfica, cuya extensión está perfectamente delimitada.

- Que exista la administración de los sacramentos y la protección espiritual de esos fieles.

- Por lo tanto, un grupo de familias depositarias de virtudes y tradiciones respetables, unidas por la fe que profesan.

De este modo la Parroquia es un territorio con una jurisdicción además de sacramental, de administración de valores y formación espiritual. Esto es lo que dio el fundamento a la Iglesia Católica para realizar su labor educativa con sus fieles. Los parroquianos, como miembros de una Parroquia, tienen la obligación de vivir en esa área, porque de lo contrario dejarían de serlo. Su intencionalidad de estar en permanencia les da la posibilidad de ser socorridos espiritualmente tanto a los que dirigen las familias, como a sus hijos y a las mujeres (sean casada, solteras o viudas).

\section{La labor parroquial}

En los inicios estructurales de las parroquias, los obispados no tenían demarcación definitiva y precisa. Primero por la forma como se establecían los templos, ya sea en forma de capillas, iglesias o Catedrales; después por la movilización migratoria que tenían las personas debido a las invasiones bárbaras en la Europa medieval. Es así que a partir del siglo IV de nuestra era, las parroquias se convirtieron en comarcas rurales y luego en el siglo IX se concretaron en las zonas urbanas. El Derecho Canónico fijó las características, aunque muchas veces la lengua, la nacionalidad o el grupo 
social fue preponderante para determinar los límites parroquiales. Muchos Concilios discutieron sobre esa característica: la parroquia espiritual y la parroquia geográfica. Al final se estableció la conveniencia de unir ambas acepciones.

En la baja Edad Media la parroquia tenía ya una estructura como un ente administrativo dentro de los obispados. Sin pretender discutir o interpretar el Derecho Canónico, la estructura que nos ha llegado hasta hoy es la siguiente:

- La comunidad religiosa parroquial: es el conjunto de sacerdotes y religiosas que viven en la parroquia. Su labor es pastoral. Son el elemento directriz dentro de la parroquia.

- El consejo parroquial: es la reunión de los religiosos y los seglares colaboradores. Es la comunidad que dirige la parroquia dentro de su marcha progresista. Este Concejo es una especie de Cabildo Parroquial formado por vecinos honorables, colaboradores, llenos de espíritu emprendedor que hacen posible las obras de bien común. Entre las personas que lo forman se ven médicos, ingenieros, obreros, etc., que trabajan «ad honoren» para la comunidad. Su elección es muy diferenciada, desde el ofrecimiento, la división por barrio, los nombramientos por los grupos que forman la parroquia hasta la delegación de alguna de las autoridades religiosas. Su labor es discutir los problemas de la parroquia como son los asistenciales, la catequización, el trabajo espiritual con los jóvenes, la educación religiosa de los parroquianos, entre otros.

- La acción parroquial: son las diferentes actividades que realizan los elementos que forman la Parroquia. Entre ellas tenemos: 
a) La acción pastoral: es una de las labores más proficuas dentro de la Parroquia. En su conjunto están referidos al afianzamiento de los ejercicios religiosos y eclesiásticos. Tenemos el caso de la administración de sacramentos, trabajos con grupos parroquiales: jóvenes, enfermos, damas, hermandades, convertido en retiros y ejercicios espirituales, apostolado de la oración, encuentros pre y posmatrimoniales, cursos bíblicos, boletín parroquial, etc.

b) La acción social: son las acciones en beneficio de los estratos menos favorecidos socialmente. En ellos se da testimonios de los valores cristianos de ayuda al prójimo. Aquí se tienen: los dispensarios para enfermos, el comedor para menesterosos, el centro para madres desamparadas, el albergue nocturno para viajeros, el albergue para menores desamparados, hasta las cooperativas de crédito o de consumo.

c) La acción educativa: es la misión que tiene la iglesia de catequizar a sus fieles, usando para ello los diferentes medios de formación educativa. Esta educación debe estar acorde con los valores religiosos y patrióticos.

\section{LA ESCUELA O EL COLEGIO PARROQUIAL Y LA PARROQUIA}

\section{La labor educativa de la parroquia}

Desde los inicios de la institución parroquial como parte de la Iglesia Católica, hubo la preocupación para que sus fieles recibieran junto con el mensaje espiritual de adoctrinamiento de la fe, una adecuada formación moral y educativa. Esta preocupación hizo de las parroquias, emporios de la cultura en la Civilización Occidental. El párroco se convirtió así en el eje 
impulsor de cultura de sus feligreses para la formación de centros que con el correr de los tiempos, se transformaron en centros de erudición y estudio.

En efecto, lo que al comienzo fue el motivo de adoctrinamiento, para el buen ejercicio de la fe y la religión, terminó convirtiéndose en un centro educativo catequético con alcances de continuidad de estudios más serios y prolongados. Estos estudios se dieron en los antros de la misma parroquia, convirtiéndose en la escuela parroquial.

La escuela parroquial llegó a representar el reflejo de la labor educativa de la Iglesia. Mejor: en el lugar que se impartía los adelantos culturales de la comunidad cristiana. A ella siempre se acudía para buscar cosas del buen saber de Dios y el mejor saber de los hombres.

\section{La escuela parroquia. Características generales}

Entonces, la Escuela Parroquial es un centro de formación cultural y la presencia de la Iglesia a través de la enseñanza escolarizada que reciben los hijos de los fieles. La finalidad primera es tratar de juntar a todas aquellas familias que están unidas espiritualmente por la religión y la fe. Después, convertir a la escuela en el núcleo de las familias de un lugar, en el centro de la formación y hermandad de los niños, razón que muchas veces se pierde en la escuela fiscal.

La Iglesia y el Estado son los dos grandes instituciones a las cuales recurre el ciudadano para lograr la formación de sus valores cívicos. En ambas, la familia es la esencia de su constitución, por lo tanto se complementan. Del encuentro de ambas muchos pueblos han forjado su grandeza. El estado da a las familias el deber y el derecho inalienable de educar a sus miembros, la Iglesia se preocupa del destino eterno del hombre, ambas también protegen y estimulan el bienestar de los ciudadanos: 
Esta presencia de la Iglesia en la escuela a través de sus instituciones, se apoya en la naturaleza de las sociedades pluralistas y en el debido respeto a los derechos de unos ciudadanos que son y se reconocen católicos y al derecho de la Iglesia a establecer y dirigir escuelas. En este sentido, la escuela católica debe tener todos los elementos propios de una escuela. Pero además, debe ser también una escuela de calidad participativa, y ser un servicio público a la sociedad desde el valor humanizado del evangelio. ${ }^{2}$

La necesidad de dar educación a muchos niños, adolescentes y jóvenes; las parroquias de las diócesis han erigido distintas instituciones escolares. Una de ellas, la escuela parroquial, se constituye en una riqueza y en una honra para nosotros los católicos, al poner de manifiesto la preocupación por la promoción integral de los fieles y ser testimonio y aval de la misión evangelizadora.

\section{Desarrollo de las escuelas $\mathrm{Y}$ LOS COlegios parroquiales católicos en el Perú}

\section{Los origenes de la escuela parroquial}

a. El nacimiento de la escuela parroquial en la Europa bárbara

Durante la etapa de las invasiones bárbaras, los pueblos de la Europa occidental estaban prácticamente paralizados en su labor educativa y en general en su desarrollo cultural. La Iglesia, con la labor paciente de sus monjes y religiosos, pudo salvar tesoros bibliográficos de la etapa grecolatina,

2 Información procedente del Colegio Parroquial San Cristóbal Mártir de Picassent. 
muchos de los cuales se hubieran perdido. Esta etapa mal llamada de la «edad oscura», fue el inicio de la recuperación del saber occidental a través de conventos y parroquias.

$\mathrm{Al}$ principio las escuelas monacales y conventuales, fueron las débiles luces que iluminaron para que Europa se mantuviera dentro de la grandeza de los restos humanísticos creado por griegos y latinos. La preocupación cristiana favoreció para que el saber cristiano contribuyera, junto con lo grecolatino, en la formación del crisol que hoy se llama Cultura Occidental.

Fue en esos momentos cuando nació la escuela elemental de radio más basto que la Episcopal (formada para eclesiásticos), es decir, una escuela para seglares y con un carácter presbiteriana, para evangelizar a los bárbaros. Todas ellas en zonas rurales, donde la Iglesia catequizaba y convencía a los idólatras y gentiles para que tomen la nueva religión. En el Concilio de Vaisón en 529, se discutió la preocupación de la evangelización y se ordenó a «todos los sacerdotes encargados de parroquias para que reciban en calidad de lectores a jóvenes, con el fin de educarlos cristianamente y enseñarles los salmos y lecciones de escritura y toda la ley del señor, de modo que se pueda preparar entre ellos dignos sucesores» (cf. Luzuriaga 1961). Esta recomendación fue repartida por otros Concilios como el de Mérida en España, en el año 666.

En el Sínodo de San Omer (Francia), el año 1183, se mandó a los Obispos que no solo se limitaran a las Escuelas Catedrales, que eran una especie de escuelas de nivel secundario junto a las iglesias Mayores, sino que se extendiera su inspección a las Escuelas Parroquiales, adscritas a las Iglesias menores, que tenían un carácter elemental. Se ordenaba así mismo que en las villas y aldeas de las Diócesis, sean restauradas las Escuelas Parroquiales allí donde todavía se mantengan y dentro de las posibilidades crearse nuevas. 
Desde este momento la Escuela Parroquial tomó características que todavía se mantienen en su estructura general. Por ejemplo, la manutención tanto del local como del profesorado, sería tomado por personas distinguidas que ayudarían con donaciones voluntarias. El estado contribuiría con una cooperación significativa. Así lo instituyó el emperador Carlomagno, famoso estadista francés, quien pensó de esta manera hacer llegar la educación al pueblo. La proclama de esta autoridad para todo el imperio, que se dio en el año 789, atestigua el apoyo del gobernante para las escuelas parroquiales (cf. Luzuriaga 1961).

Durante la Baja Edad Media la escuela parroquial se estacionó. La iglesia tuvo mayor dedicación a los colegios Mayores y a las Universidades. En ambas instituciones se preparaban a los doctores de la iglesia y tales personajes dieron rango a la cultura que se expandió por todo Europa. Sin embargo, en las parroquias, las autoridades religiosas, siguieron manteniendo la labor educativa de catequesis, cuyo producto final era la creación de un centro elemental de instrucción para los hijos de los fieles.

b. La escuela parroquial y la reforma protestante

El movimiento de reforma religiosa, surgido en el siglo XIV en Europa Occidental, determinó cambios en la Escuela Parroquial. Los movimientos protestantes utilizaron a esta clase de centros educativos como medio de proselitismo entre los niños, los jóvenes e incluso los adultos. Se trató de imponer las ideas protestantes dentro de una cooperación entre la Iglesia y el Estado. Las escuelas elementales, adjuntas a las parroquias, que hacían difusión cultural, también se utilizó para llegar al pueblo. De esta forma se especificó el estudio de la lengua nativa, la interpretación de la Biblia, el manejo de los clásicos latinos y, sobre todo, el aprendizaje 
de los preceptos de las iglesias reformadas. Ejemplo de ello es cómo en Alemania se crean escuelas luteranas con el apoyo del Duque de Sajonia y en Escocia el calvinista Jhon Knox escribe en su libro De la disciplina para la iglesia escocesa que "toda gramática y la lengua latina debe ser enseñada por un maestro capacitado, y en el campo, el ministro debe cuidar de los mismos para instruirlos en los primeros elementos y especialmente en el catecismo" (cf. Luzuriaga 1961). De igual modo se especificaba que el párroco era el Director de las escuelas parroquiales y debería educar para crear un feligrés para la iglesia y un ciudadano para la república y la sociedad. Esta última característica de la hoy escuela parroquial, llegaría a nuestro país bajo la influencia anglosajona, en la década del cincuenta del siglo xx.

\section{La llegada de las escuelas parroquiales al Perú}

España, el país que colonizó al Perú y trajo la cultura occidental, fue un país profundamente católico; por lo tanto, el establecimiento de escuelas en las parroquias se tuvo que dar, pero en una forma diferenciada a la que ya existían en la Europa renacentista. El carácter de esta situación también trajo a los misioneros e hizo que la encomienda (reparto de tierras y de indígenas) sirviera de base al establecimiento de la parroquia (cf. Vargas 1953). El encomendero era el encargado, según la corona española, para dar apoyo religioso al indígena. El soldado español llamaba a un religioso para que catequizara al siervo indígena en nombre de Dios y del rey. Entre ambas autoridades, muchas veces, cometían tropelías explotando a los fieles y dieron motivo para que los Caciques levantaran su voz de protesta ante las autoridades. El Consejo de Indias tomó medidas represivas y pidió a los Obispos para que nombraran oficialmente doctrineros. 
El Primer Concilio Limense de 1552, a los pocos años de fundada Lima, presidido por el obispo Toribio de Mogrovejo (elevado después a los altares como santo), y para el cual acudieron Obispos de Quito, Cusco, Santiago de Chile y Río de la Plata, determinó, con disposiciones adecuadas, las reglamentaciones sobre las instalaciones de las parroquias y de los curatos. Por ejemplo, en su Acta II se indica la percepción del catecismo para los indios, pidiéndose que se establezca una Iglesia en el lugar donde viviera el caique principal o en el pueblo del cacicazgo. Además se obligaba a construir de inmediato una capilla, en la cual se enseñaría la doctrina, se hiciera el rezo y el recogimiento de los fieles. Cuando la población era abundante se haría una iglesia mayor si fuera conveniente. Y si es verdad la enseñanza era para los indios, se disponía también para los morenos y mulatos, según su habilidad y oportunidad (Actas del Primer Congreso de Historia Eclesiástica 1990).

En el Segundo Concilio de 1567, se determinó que por cada doctrinero se le señalaría 400 indios casados (familias) con la obligación de dominar la lengua del lugar. Se establecía, igualmente, que la enseñanza era para hacerlos vivir «con orden y policía, tener limpieza, honestidad, buena crianza" y otras costumbres tendientes a regular todos sus actos dentro de un ámbito cristiano. En esta misma línea de mejoramiento social y material de las escuelas se hallaban los hospitales.

En 1560, el establecimiento de parroquias era masivo, por ejemplo en el Cuzco se tenía 6 y Lima 108 (cf. Vargas 1953). Los religiosos encargados de parroquias estaban obligados a establecer centros donde se enseñara doctrina cristiana, cánticos y rezos, hasta realizar visitas a lugares apartados por parte del párroco, con el fin de mantener y difundir la fe en los nuevos territorios conquistados.

Para tener idea claro de lo que se hacía en las incipientes escuelas, transcribimos las palabras del Padre Orá un religioso visitador de curatos de 
la época: «para todas estas cosas es muy necesario que haya escuela y maestro de ella, y cantores diputados, y pagados con salario suficiente, donde sean enseñados los muchachos a rezar la doctrina, y leer y escribir, cantar y tañer, y de la escuela salgan hábiles en la doctrina, para enseñarle a todo un pueblo para ser mejor doctrinado y rígido, y donde no la hubiere faltará todo lo dicho, de doctrina, música, ornato y servicio de las iglesias, altar y coro» ( Actas del Primer Congreso de Historia Eclesiástica 1990: 417).

Entonces, además del valor evangelizador y religioso de las «doctrinas o parroquias", se agregaba para los pobres una función humanitaria y cultural. Los doctrineros fueron los primeros maestros que se preocuparon por enseñar a leer escribir, cantar, aprender las labores manuales y artesanales, todo ello con una labor pedagógica muy importante. Desde este momento, en plena etapa inicial de la colonia, podemos decir que la Parroquia y la incipiente escuela parroquial, adquieren sus peculiaridades: nace con un fin catequista y formativo de valores religiosos y ciudadanos.

\section{La escuela parroquial en la colonia}

1.1. El establecimiento de la escuela parroquial y las órdenes religiosas

Como se ha visto en los diferentes Concilios celebrados en Lima, realizados por las autoridades eclesiásticas, se hacía constar legalmente la existencia de la escuela parroquial. Según anotamos en el Concilio de 1552 (Constitución 74, Parte II), se habla claramente de los maestros y las escuelas que enseñaban doctrina. El Concilio de 1583, capítulo 43 de la Acción II, encarga a los sacerdotes el establecimiento definitivo de tales centros educativos dentro de una nueva modalidad: tratar de llevar la doctrina al pueblo. Por su parte 
la autoridad Real también llegó a establecer mandato para evitar que los encomenderos eludieran sus responsabilidades: la Real Cédula del 19 de octubre de 1556 disponía que todas las catedrales tendrían un colegio para mestizos e indios.

Por su lado, las congregaciones religiosas pedían ayuda económica y el reconocimiento ante las autoridades políticas y religiosas. Tal es el caso del padre Fray Tomás de San Martín, eminente dominico, quien pidió a Carlos V ayuda para sus sesenta escuelas parroquiales fundadas por su orden en el Perú. Los agustinos tenían sus acuerdos de labor misional para poner escuelas donde pudieran aprender los nativos a leer, escribir y contar, del mismo modo el manejo de las artes y oficios para sacar hombres de trabajo y honestos. Los franciscanos tenían escuelas muy importantes, como la de San Andrés de Quito, donde se educaba un hijo de Atahualpa, para dar sustento y vestido (cf. Vargas 1953), y los jesuitas, con el Padre Francisco del Castillo, pedían apoyo para una escuelita gratuita instalada en la Parroquia de Nuestra Señora de los Desamparados (tema que ampliaremos más adelante), al costado de la casa de gobierno, donde se enseñaban las primeras letras, aritmética y canto, a niños pobres de bajo el puente (Rímac). El obispo del Cusco Don Manuel Mollinedo se esforzaba para que en las villas y pueblos de su Diócesis hubieran escuelitas de este género junto a las parroquias. De igual modo en Arequipa Don Antonio de León declaraba rentas para las escuelas que estuvieran junto a las iglesias especialmente jesuíticas. En 1659, el espíritu religioso de los seglares, inspiró la creación de escuelas para la instrucción elemental en Lima y otros lugares del país, pero bajo la regencia de religiosos adjuntos a las parroquias. El ejemplo más característico fue la de Santa Cruz de Atoche, para niñas, fundado por Mateo Pastor de Velasco y su esposa Doña Francisca Vélez Michel, quienes le asignaron una renta anual de 15832 pesos proveniente de sus bienes (Vargas 1953). Vamos a referir 
con algunos detalles, para ver cómo funcionaba en la colonia una escuela parroquial. En el primer caso, en la escuela dentro de una zona urbana y, en el segundo, en la zona rural.

La Escuela de Nuestra Señora de los Desamparados (demolida en 1935 para ampliar y remodelar el Palacio de Gobierno durante la gestión del presidente Oscar R. Benavides) fue establecida por el religioso jesuita Francisco del Castillo el 10 de enero de 1666, junto a una capilla que funcionaba al costado de la casa de Pizarro. Al respecto, el padre Armando Nieto Vélez S. J. relata en su obra Francisco del Castillo: El apóstol de Lima, lo que significó esta clase de colegios cuando indica «que las escuelas de las primeras letras o decurias como también se les llamaban, se impartían en el Virreinato los rudimentarios de las primeras letras (leer, escribir, contar), así como nociones de catecismo». Al día siguiente de la inauguración, los primeros alumnos estrenaron la escuela. Los primeros años estuvo dirigida por el hermano Diego de la Maza. Durante dieciséis años fue maestro en la fundación el padre Francisco. Llegaron a frecuentar la escuela 300 alumnos. A los más necesitados se les proporcionaba cuanto hacía falta para sus clases: papel, plumas, tinta. La escuela estaba puesta a la doble advocación: La Virgen María y de San José. Asumió también para alumnos de buena condición económica, pero la mayor parte eran los hijos de negros, mulatos y demás gente plebeya, a quienes el padre Francisco trataba con dulzura mirándolos con igualdad. Después del fallecimiento del padre Del Castillo en 1673, la escuela quedó consolidada y el alumnado aumentó a más de 400, llegando a tener bienhechores como el Virrey Conde de Lemus, el noble Juan Infante Trujillo que donó en 1684, para el mantenimiento de la escuela, la hacienda Ingenio en el valle de Huaura; otro fue don Eusebio Dávalos quien cedió los réditos de una estancia en Canta y Simón Ruíz Díaz quien legó una suma de pesos (testamento). El desarrollo de la Escuela y en 
general la evolución de la educación en el Perú, anota el padre Nieto, han ratificado la avanzada intuición del Padre del Castillo, al que hay que señalar - ya a mediados del siglo XVIII — como un «auténtico propugnador de la educación popular» ( cf. Nieto S.J. 1992).

En las zonas rurales el párroco se confundía con el misionero. La estructura de la escuela parroquial era algo especial. Los profesores eran tanto religiosos como civiles. Sacristanes o novicios enseñaban la doctrina cristiana, para los civiles, gente que había realizado algunos estudios, cuando se tenía la enseñanza de las artes y oficios o algunas cosas de gramática. Los profesores civiles eran pagados con aportes de los fieles, o algunos fondos que aportaba el cabildo cercano o los fondos sacados de la parroquia. La acogida de los alumnos era más liberal: podían ser los hijos de los caciques, mestizos o criollos y, aunque rara vez, hijos de ricos encomenderos que mantenían el Colegio. Se acostumbraba el pago con alimentos o servicios de los estudiantes. Cada muchacho pagaba al año un «patacón» además un "almud de maíz y otro de papas», siendo los huérfanos dispensados de paga, pero tenían que traerle al maestro un haz de leña todos los domingos. Si el profesor tenía tierras de sembrar, le ayudaría en su sementera. En el caso que los aportes del alumnado no alcanzaba para el sustento, se podía tomar rentas de impuestos o fondos de la iglesia, con previa autorización de las autoridades. Lo que se enseñaba eran temas simples de aritmética, religión y lectura, pero después se agregó la música y el canto hasta llegar al trabajo artesanal con un taller de artes y oficios (cf. Vargas 1953).

Es importante anotar que en esta clase de escuela, junto con la enseñanza elemental de las letras, se instruía con fines muy prácticos. Esta enseñanza despertó en los naturales el amor al trabajo, favoreciendo las labores necesarias para la buena marcha del adoctrinamiento de los fieles. El testimonio de esas escuelas han desaparecido en algunos pueblos de 
provincia, pero ha quedado las fabulosas obras de alto contenido artístico en el interior de las Iglesias y capillas, lo cual nos dice de la laboriosidad y la habilidad de la gente simple del pueblo. Todavía vemos la sacristía artística, los altares y los púlpitos trabajados, los órganos con que se hacían las misas, las imágenes con las cuales se celebraban las fiestas, como producto de la herencia que un día funcionó una escuela parroquial en la etapa colonial.

\section{2. La escuela parroquial y la escuela para caciques}

Es necesario delimitar los ámbitos entre la escuela parroquial y la escuela de Caciques o Curacas. Ambas se dieron en ese mismo tiempo y eran para la difusión de la religión en el pueblo conquistado. Sus diferencias estuvieron bien marcadas, desde sus fines, su estructura y su funcionamiento. Ambas también fueron dirigidas para ayudar a los súbditos del rey en la evangelización de sus almas. Pero su duración dentro de la educación colonial peruana fue desigual, mientras la primera sobrevivió a los cambios de estructuras políticas, económicas, sociales y religiosas; la segunda acabó cuando cumplió su cometido de evangelización y sometimiento político cultural. Vemos con el siguiente cuadro tales diferencias:

Diferencias entre la escuela parroquial y la escuela para caciques

\begin{tabular}{|l|l|l|}
\hline \multicolumn{1}{|c|}{ Características } & \multicolumn{1}{|c|}{ Escuelas Parroquiales } & \multicolumn{1}{c|}{ Escuela de Caciques } \\
\hline \multirow{2}{*}{ Fines } & $\begin{array}{l}\text { Dar cultura elemental a los pobres, } \\
\text { catequizar almas para la iglesia, } \\
\text { pero enseńándoles cosas de moral, } \\
\text { artesanía y conocer el catecismo. } \\
\text { Labor de caridad de la iglesia, pero } \\
\text { instruyendo y educando. }\end{array}$ & $\begin{array}{l}\text { Para españolizar al indígena } \\
\text { subyugado. Hacerlo culto e } \\
\text { intermediario entre la masa } \\
\text { indígena y el gobernante español. } \\
\text { Se obligaba la lealtad al Rey y } \\
\text { sumisión a lo religioso. }\end{array}$ \\
\hline
\end{tabular}




\begin{tabular}{|c|c|c|}
\hline $\begin{array}{l}\text { Características } \\
\text { de la Institución }\end{array}$ & $\begin{array}{l}\text { Se encontraban al costado de las } \\
\text { Iglesias, tanto en zona urbana como } \\
\text { rural. }\end{array}$ & $\begin{array}{l}\text { Estaba en Lima y en el Cuzco. } \\
\text { Por su forma clasista, para nobles } \\
\text { indígenas, tenía local y rentas } \\
\text { propias. }\end{array}$ \\
\hline Usuarios & $\begin{array}{l}\text { Era para la gente menesterosa, los } \\
\text { indígenas pobres, los mulatos y } \\
\text { mestizos. También para los huérfanos } \\
\text { o hijos de españoles desheredados. } \\
\text { En algunos casos, hijos de nobles } \\
\text { españoles que ayudaban a mantener } \\
\text { la escuela. }\end{array}$ & $\begin{array}{l}\text { Para los hijos mayores de Curacas } \\
\text { Principales, o los sucesores de esos } \\
\text { príncipes(parientes cercanos), en } \\
\text { caso de no tener hijos el curaca } \\
\text { principal. Los usuarios llevaban } \\
\text { uniformes y estaban internos. Las } \\
\text { graduaciones eran espectaculares. }\end{array}$ \\
\hline Los Profesores & $\begin{array}{l}\text { Eran tanto religiosos como civiles: } \\
\text { Párroco era el director y el sacristán el } \\
\text { ayudante. Eran pagados por los fieles } \\
\text { con alimentos, servicios o con fondos } \\
\text { de la parroquia. }\end{array}$ & $\begin{array}{l}\text { Eran profesores especialmente } \\
\text { escogidos por las autoridades } \\
\text { religiosas o políticas. } \\
\text { Regularmente doctos clérigos en } \\
\text { teología y dominio del idioma } \\
\text { nativo. }\end{array}$ \\
\hline Las asignaturas & $\begin{array}{l}\text { No eran uniformes ni reglamentadas } \\
\text {,en general se enseñaba artes y oficios, } \\
\text { gramática simple(leer y escribir), } \\
\text { doctrina cristiana (catecismo), mucho } \\
\text { de testimonio moral y religioso. }\end{array}$ & $\begin{array}{l}\text { Asignaturas que hoy irían entre } \\
\text { la secundaria y estudios general } \\
\text { universitarios. } \\
\text { Desde latín, teología, gramática, } \\
\text { hasta artes y labores agrícolas. }\end{array}$ \\
\hline Las rentas & $\begin{array}{l}\text { Especiales entregas de fieles } \\
\text { filántropos, mantenimiento de los } \\
\text { fondos de la parroquia, algunos } \\
\text { Cabildos aportaban de sus rentas. Los } \\
\text { huérfanos no pagaban, pero donaban } \\
\text { sus servicios. }\end{array}$ & $\begin{array}{l}\text { El estado solventado con } \\
\text { impuestos que el rey determinaba. } \\
\text { Hubo bienhechores, entre los que } \\
\text { estaban las comunidades de los } \\
\text { propios usuarios. }\end{array}$ \\
\hline $\begin{array}{l}\text { Duración en el } \\
\text { sistema educativo } \\
\text { peruano }\end{array}$ & $\begin{array}{l}\text { Se mantuvo durante la colonia, se } \\
\text { transformó en el siglo XIX en colegio } \\
\text { importante de la iglesia y adquirió su } \\
\text { forma definitiva en el siglo XX. }\end{array}$ & $\begin{array}{l}\text { Desde el siglo XVII hasta el siglo } \\
\text { XVIII. Desaparecieron con el } \\
\text { advenimiento de los movimientos } \\
\text { de rebeldía indigenista. }\end{array}$ \\
\hline
\end{tabular}


La escuela parroquial, como hemos visto, fue toda una estructura en la educación colonial. Sin quererlo se convirtió en una escuela elemental colonial, aunque no reconocida en su nivel primario. Tampoco se integró en un sistema regular de estudios. Muchas de estas bases quedaron como esencias de la actual escuela parroquial, por ejemplo, la escuela como producto de la comunidad de un barrio o un pueblo y la parroquia, con su labor religiosa y educativa que progresivamente se convirtió en otra de las células de nuestra nacionalidad.

\section{La escuela parroquial durante la independencia}

\subsection{San Martín y los colegios parroquiales}

El padre Klaiber explica en su obra La Iglesia en el Perú, que la independencia no presentó un cambio radical en la iglesia. La crisis fue soportable y el liberalismo, motor de las nuevas ideas, afectó a una élite muy pequeña, dejando casi intacta a las estructuras sociales populares. El nuevo estado nacional convivió con la Iglesia de la manera como lo había hecho en la Colonia. Los patrones socioeconómicos y educativos siguieron casi iguales para el pueblo. En el campo y los barrios populares, los curas seguían cobrando sus primicias y la gente seguía su vida diaria como si la independencia no se hubiera dado en el país. La educación era para pudientes, seguía existiendo la distinción profunda de clases sociales y los prejuicios de raza. $\mathrm{Al}$ no cambiarse casi nada de la estructura socioeducativa, los libertadores se convencieron que el cambio vendría por la instrucción escolar. Por eso, San Martín afianzó mediante órdenes, ciertos aspectos educativos para la marcha del nuevo Estado. Por ejemplo, según el decreto del 23 de febrero de 1822, todos los conventos regulares existentes en el territorio tendrían escuelas 
de primeras letras y los prelados respectivos nombrarían a los preceptores correspondientes (cf. Basadre 1969). Se establecía las escuelas de primeras letras dirigidos por religiosos de la comunidad.

Según Mc Lean (1950), la educación al inicio de la república se encontraba en los centros escolares para niños que se daba en las porterías de los conventos o en los lugares vecinos a las parroquias. La dirección de estos centros estaba en mano de frailes, clérigos o sacristanes. La enseñanza consistía en hacer repetir el catecismo, utilizar la palmeta y el chicote (látigo pequeño) para corregir los errores en el aprendizaje. En todas estas escuelas el trabajo era unidocente y el método básico era el lancasteriano: los maestros exigían la memorización de textos, y el profesor enseñaba al alumno de mayor aprendizaje para que este a su vez cooperase en el estudio de sus compañeros.

\subsection{La primera constitución y la educación religiosa}

En 1822, el Congreso Constituyente hizo realidad la primera carta fundamental que se puso en vigencia el año 1823. En ella se confirmó el ideal de la vida democrática expresando que la instrucción era de necesidad común y que la república daba igualdades para todos los individuos (cf. Basadire: 1969). En cuanto a la educación católica se refería con el deber de enseñarla como una característica en el logro de una «buena conducta» entre los educandos.

Los documentos que se dieron posteriormente sobre la reglamentación de la educación, no mencionan específicamente sobre las escuelas parroquiales. Se entendería que son involucrados como parte de la educación pública básica, pero la Parroquia sigue siendo un eje educativo en las comunidades. Por ejemplo, eran las Parroquias los centros en donde se 
hacía la elección de los cuerpos edilicios por los colegios electorales. Desde esa misma parroquia se controlaba las acciones educativas, la salubridad, el ornato, hasta las acciones morales de los ciudadanos de la comunidad. Todo fue desapareciendo a medida que se dejó sentir la influencia bolivariana y el libertador convirtió al estado en una administración más político-centralista (1826-1839).

\subsection{Bolívar y la constitución vitalicia}

El 16 de agosto de 1825, al dar Bolívar la Constitución Vitalicia, se dispuso que en todas las porterías de los conventos y parroquias se establecieran escuelas de primeras letras, debiendo instruirse a los religiosos de la misma orden, dotados de inteligencia y moralidad, para que las administraran y mantuvieran con las rentas de las instituciones religiosas.

Visto la gran indiferencia de los padres por la educación de sus hijos y las reformas político-social que se iniciaba en la década de 1830, el Concejo parroquial se trasformó en un eje que inspeccionaba la educación, siendo muchas veces el párroco, dentro de los municipios, quien presidía el jurado que tomaba los exámenes finales. La escuela parroquial de la colonia irremediablemente se fue trasformando en la escuela fiscal de nivel elemental de la república.

3. La escuela parroquial en el Perú Republicano del siglo XIX

\section{1. El general Santa Cruz y las escuelas parroquiales}

En medio del cambio, de la Colonia a la República, la iglesia católica se encontró con una serie de crisis. El nuevo gobierno republicano reclamó para sí el derecho de patronato sobre la Iglesia y provocó de esta manera 
una crisis de jerarquía. Durante 15 ó 20 años la mayor parte de las diócesis estuvieron vacantes. Los liberales cerraron varios conventos y anularon la supremacía de las parroquias, sobre todo en el campo educativo. Su propósito era controlar la Iglesia a fin de ponerla al servicio del Estado republicano. La iglesia por ello se empobreció, pero a la vez se sirvió de los regímenes anárquicos acogiéndose a su protección y pudo seguir siendo una institución influyente dentro de la república.

En 1823, la educación —o instrucción como se le llamaba-, dependía del Ministerio de Gobierno y en 1826 estaba dentro de la Secretaría de Estado en el Despacho del interior. A partir 1837, el General Andrés de Santa Cruz, por Decreto del 4 de febrero, creó el Ministerio de Instrucción Pública, Beneficencia y Negocios Eclesiásticos. En una de sus especificaciones determinaba que el estado intervenía directamente en los asuntos de la Iglesia tanto en el aspecto de nombramiento de prelados como en la supervisión de lo educativo. Los curatos (parroquias) eran designados por el gobierno de turno, a propuesta de los Obispos, y según ley del 12 de noviembre de 1832, se declaró secularizada las escuelas parroquiales todavía existentes, las cuales serían dirigidas exclusivamente por seglares. Del mismo modo cuando haya vacantes, se previeran por concurso con seglares o con exclaustrados (ex religiosos). Los curatos deberían favorecer a quienes se hubieran preocupado por el sostenimiento y adelanto de las escuelas (Circular del 30 de enero 1828). En el quinquenio de 1834-1839, el gobierno insistió en atender a las escuelas de conventos o parroquias, que según se sabía de funcionamiento irregular. Se exigió a los religiosos para que cumpliesen su deber de difundir la instrucción, pidiendo el cumplimiento de una circular existente desde el 11 de mayo de 1830.

En los años venideros a la Confederación Perú-Bolivia se insistió por esta clase de colegios (Oficio del 4 de enero de 1840), donde se trató de hacer 
cumplir disposiciones que jamás se realizaron. El historiador Jorge Basadre dice al respecto que en las escuelas de las porterías de los conventos solo se enseñaba a leer, escribir, contar y aspectos de la doctrina cristiana. En 1840, funcionaban esta clase de escuelas junto a Santo Domingo, San Agustín y San Francisco; en provincias muchas de ellas habían sido fiscalizadas, otras cerradas, pero todavía en 1869 una circular de abril intentaba ponerlas en vigencia (cf. Basadre: 1969).

\section{2. Ramón Castilla y los cambios en la educación peruana}

Entre 1850 y 1855, el Presidente Ramón Castilla promulgó una serie de leyes que modificaron los aspectos del sistema educativo existente, mientras la Iglesia después de soportar los embates del liberalismo, se afianzaba en la Constitución moderada de 1860. La Iglesia mantenía su estatus legal y privilegios de ser protegida por el Estado.

En efecto, se reglamentó la instrucción y se declaró al Magisterio como una profesión dentro de las existentes. La educación se dividió en niveles: primaria, secundaria y superior, se estableció los cursos para cada grado; se dispuso que los textos fueran gratuitos para el alumno y se asignó los sueldos a los nuevos profesionales. En lo que toca a la enseñanza popular, debería ser general y sencilla, siendo las primeras letras para niños de tres a seis años. Las de artes y oficio para perfeccionar la educación del artesano, de infancia y la de escuela normal, que sería modelo entre las primeras letras. Su dotación de maestros era variable según las circunstancias de los pueblos y se cubría los gastos con los fondos propios de las escuelas. El dinero salía de las cuotas señaladas por las comisiones parroquiales para que los padres que podían pagar lo hicieran y si todo ello no bastaba, recibían ayuda del Estado. La instrucción de los pobres era de carácter gratuita. 
Los párrocos eran los síndicos y jurados en los exámenes de fin de año. Eran nombrados por el municipio y su actuación se dejaba sentir en toda la escuela primaria que podía ser de primer y segundo grado. En los primeros se enseñaba lectura, escritura, nociones de aritmética, de gramática, de teneduría de libros y economía política (Art. 7). En las segundas, además de escritura y lectura, se aprendía aritmética completa, gramática, religión, regla de moral práctica, urbanidad y nociones sobre contratos más normales, sobre las penas aplicables y los delitos comunes (Art. 7). Como vemos, el reglamento no mencionaba específicamente el nombre de Escuelas Parroquiales, pero se supone que estas se encontraban dentro de la enseñanza popular. Precisamente en esas escuelas fiscalizadas, el párroco, por su formación cultural siguió ejerciendo su autoridad educativa y era el eje dentro de la comunidad.

El reglamento de 1855 duró con ciertas modificaciones hasta 1876, y fecha en la que el presidente Manuel Pardo reglamentó nuevamente la educación. Según la recopilación de Filiberto Ramírez en su Leyes y resoluciones vigentes en materia de instrucción de 1876, la obra de Félix Cipriano Coronel Zegarra sobre La educación popular, de 1872, y la Guía estadística de Luis Benjamín Cisneros en su Informe sobre la educación en Lima no se menciona reglamentación alguna para las escuelas y colegios parroquiales, aunque si se remita a la llamadas escuelas libres dentro de las cuales posiblemente estuvo una que otra de esta clase. Nos parece que todas ellas casi desaparecieron y otras pasaron a transformarse en Municipales, pero con intervención del párroco.

Las ideas liberales cuya influencia trajo discusiones sobre la limitación de la Iglesia y el Estado, influyó en el desarrollo del sistema educativo existente. La influencia de su difusión se anotó en los periódicos, el panfleto y la discusión parlamentaria. Para ver con mayor claridad esta 
polémica veamos lo que decían dos voceros: El constitucional, de ideas liberales, editado por Gonzales Vigil y El Católico cuyo mentor era el clérigo Bartolomé Herrera.

\section{3. La polémica sobre la educación religiosa y las ideas liberales}

El Constitucional, editado en 1858, criticaba la educación popular en manos de los religiosos. Decía que estos formaban fanáticos e incrédulos, siguiendo la idea de los gentiles, y que el fanatismo daba un desarrollo anormal en la vida de los pueblos. Clasificaba a las formas posibles de la educación popular: las llamadas escuelas primarias, tales como la escuela para niños, la escuela para adultos (en las noches y en los mimos locales) y las escuelas dominicales (de experiencia justificada en los Estados Unidos de Norteamérica). En otra parte, fustigaba sobre la forma cómo se llevaba la educación de las mujeres («bello sexo»), diciendo que los hombres no eran culpables de las cosas que les ocurrían a ellas, sino que la educación que recibían contribuía a la desgracia. Pedían que la educación se encuadrara en el hogar, que no sean los curas y las monjas las llamadas a reglamentar desde la Iglesia, el convento o el colegio, lo que podrían hacer los padres y las madres. Las terminologías que se usaba para denominar el producto de esta educación era de personas intransigentes, fanáticas, intolerables, partidaristas, sectarias, desde cualquier lugar que ocuparan en la república. Todo ello se notaba en la influencia de lo que hacían cuando se desempeñaban en el grupo personal donde desarrollaban su forma de vida y realizaban sus acciones como ciudadanos de la república.

El Católico, periódico editado en 1855, explicaba que la religión era la base de las operaciones educativas y abogaba por la formación del verdadero católico, ejemplo de persona que podía cumplir con los deberes 
de la vida civil y podía alcanzar la felicidad temporal. Mencionaba que la enseñanza era el gran instrumento para educar y formar el espíritu; porque instruir buenos niños era formar excelentes ciudadanos. Concluía que la religión católica educaba para los sentimientos y para que la persona diera amor, ternura y honor; con tales valores se llegaría a tener los resortes de una buena vida humana.

Este polémico enfrentamiento entre liberales y conservadores dio a la educación de mediados del siglo XIX, un carácter laico, porque a la iglesia se le combatía asociándola con la idea del coloniaje y el terror de la inquisición. Por ello, la escuela parroquial se transformó en escuela municipal y los reglamentos que se dieron tanto en 1866, como en 1867 , influidos por el liberal Simeón Tejada, certificaron este carácter.

\section{La educación católica a fines del siglo XIX}

Después de la Guerra con Chile, la educación religiosa tuvo situaciones difíciles. A los partidarios de las ideas liberales, se agregaron los partidarios de los positivistas, de los protestantes, los anarquistas y los socialistas. Las críticas eran propicias para ahondar la herida ocasionada por la derrota en la Guerra del Pacífico. El líder Manuel Gonzáles Prada proclamó en contra de todo aquello que significaba iglesia, convento, sacerdotes y monjas. La educación religiosa era la más castigada, proclamándose que los hombres formados en escuelas católicas era fanáticos, «estúpidos» y serviles.

Para contrarrestar las críticas, la Iglesia se erigió en el baluarte de los valores nacionales. El sacerdote jesuita Klaiber nos confirma este hecho cuando nos dice: «que la iglesia buscó nuevos objetivos, tales como el fortalecimiento de sus lazos con Roma, el afianzamiento de la iglesia en la sociedad, sobre todo buscando protección oficial y contribuyendo con la 
formación de los laicos en las clases altas y medias a fin de hacerlos católicos más conscientes de su fe» (1988).

Lo que se trató fue tener defensores de la iglesia entre los ciudadanos de estas clases sociales que se desempeñaban en el foro político, los negocios y la casta gobernante. Esta caracterización llevó al establecimiento en el país de los hoy llamados Colegios religiosos de primera categoría. En ellos llegaron a educarse los hijos de las clases media y alta.

5. El siglo XX y nuestros planteles parroquiales

5. 1. Las primeras décadas y la apertura de nuevos colegios religiosos

En el nuevo siglo, la Iglesia Católica buscó rehabilitarse, ya sea haciendo cambios entre las órdenes religiosas, el nacimiento de nuevas congregaciones, que tenían un espíritu misionero en el país, o dando impulso entre los religiosos para buscar una nueva acción educativa, sobre todo para la clases media y alta.

Una de esas obras se situó cuando las familias influyentes, en forma particular, auspiciaron la llegada al país de religiosos que podían dirigir la educación de sus hijos. Otro caso fue cuando los gobernantes buscaron apoyo en ciertas órdenes religiosas, tratando que con su obra evangelizadora, en lugares de la Selva o pequeños pueblos de la Sierra, afianzaran la administración del Estado.

La educación cada día se hizo más centralista. Los pocos colegios religiosos de parroquias, como hemos dicho, se terminaron transformando en colegios municipales o estatales con una dependencia y estructura de un poder central que decidía su administración y evaluación. En 1901, 
se dispuso una nueva reglamentación de la educación por parte del Gobierno, con características más científicas y centralistas. Y en 1905 se suprimió el Concejo de Instrucción Pública para asimilarlo al Ministerio de Instrucción.

Mientras tanto, la Iglesia dirigía su labor educativa como parte de su labor misional. En 1903, se fundó el Colegio de San Agustín de Lima, dentro de los claustros del convento, con religiosos que habían hecho labor educativa en las riveras de los ríos de la Selva. Otros centros, de esta orden, fueron el Colegio Santa Rosa de Chosica y el Instituto Sevilla para niñas huérfanas. Las hijas de María Auxiliadora, en 1902, fundaron en Breña un colegio para niñas. Asimismo, siguieron otras fundaciones con las mismas características en Mollendo, Arequipa, Piura, Ayacucho y Huancayo.

Los Hermanos del Sagrado Corazón, en 1909, tomaron a su cargo el Pedagógico Nacional de Mujeres (fundado en 1876), establecieron el Colegio Sophianum y sus obras educativa las extendieron a Jaén, Bágua, Bambamarca, Arequipa y Trujillo. Otro grupo muy activo fueron Los Hermanos Maristas quienes divulgaron su obra educativa en Colegios. Se dejaron sentir, desde 1909, en centros como el Champagnat de Miraflores y San José de Huacho, y demostrando su preocupación por los niños, su labor se extendió a nuevos centros educativos en Tacna, Cajamarca y Sullana.

Desde 1915 hasta 1930, las instituciones educativas religiosas siguieron creciendo. Se establecieron colegios casi todos para educar a la clase solvente económicamente. De este tiempo tenemos el Colegio San José de Cluny de Barranco, el Santa Rosa de las Religiosas Dominicas del Rosario, San Juan Bautista de La Salle (otros de la misma congregación en Cuzco y Arequipa), el Villa María y el San Antonio del Callao. 
5.2. Los cambios en la educación y la apertura de instituciones de renovación pedagógica

Los cambios ideológicos de renovación pedagógica venidos de Europa y Estados Unidos contagiaron a los ideólogos de nuestra educación como Manuel Vicente Villarán, Alejandro Deustua y José Antonio Encinas, quienes desde el libro y la cátedra, trasladaron sus ideas sobre la nueva educación al parlamento y plantearon leyes que modificaron el sistema educativo peruano, sobre todo en el desarrollo de la educación técnica. De esta manera se inició lo que sería una constante durante casi todo el siglo xx: los intentos por reformar la educación, muchos de ellos con aspectos frustrantes, de expectativas nacionales y convirtiendo a la educación en un instrumento político antes que motor de desarrollo económico y social.

Quien puso en práctica una primera reforma educativa fue el gobierno del presidente José Pardo, durante su primer gobierno (19041908): se impulsó la educación primaria, haciéndola obligatoria y gratuita, (incluyó el reparto de material de enseñanza), también se solventamos completamente las escuelas técnicas y ocupacionales nocturnas, además se dio gran impulso a la educación privada. La carrera magisterial alcanzó la jubilación y montepío para los profesores. Todo ello con el apoyo y asesoramiento de pedagogos belgas, franceses y norteamericanos.

La educación católica, en esta etapa, siguió su cauce de crear instituciones educativas para obreros y para el pueblo. Las escuelas junto a la parroquia siguieron funcionando sobre todo en lugares apartados de provincias, como parte de una labor social. Nuevas instituciones fundadas por religiosos peruanos y con visión de servicio en la labor parroquial, aparecen en el país. El ejemplo característico es la labor de las Misioneras Parroquiales del Niño Jesús de Praga, fundada por Angélica Recharte, quienes tenían 
una labor misionera dentro de las parroquias, tanto en la preparación de las personas para recibir los sacramentos, las visitas a domicilio, como la formación educativa de los jóvenes. Su obra parroquial se dejó sentir en la formación de colegios en Lima, Tacna y Tarma. La obra se había iniciado en 1930. Otra labor parecida fue la llevada acabo por La canonesa de la Cruz, establecida por Teresa de la Cruz Candamo, hija de un presidente del Perú, quien a inicios del siglo xx fundó una congregación orientada al trabajo pastoral en parroquias del cercado y del Callao. Comenzaron a enseñar en escuelas para el estado, pero extendieron su apostolado, iniciado en 1922, hacia centros educativos para jóvenes de clase social pobre en Chiclayo, Piura, Huaraz, Chimbote y Yurimaguas.

El robustecimiento de la educación católica llegó hasta el medio universitario, cuando el 24 de marzo de 1917, se oficializó el funcionamiento de la Universidad Católica del Perú. Se había culminado la idea del visionario sacerdote francés de los Sagrados Corazones, Jorge Dintilac.

\section{3. La educación católica hasta antes de la reforma de 1972}

La crisis, como la Primera Guerra Mundial y los gobiernos efímeros de 1930 hasta 1933, afectó en muchos aspectos el desarrollo del país. Sin embargo, la educación católica tomó nuevos auges con la llegada de congregaciones religiosas desde Europa, Canadá y Estados Unidos.

En 1940, se respiró democracia y el Gobierno del Presidente Prado adecuó el marco de una renovación educativa con una nueva Ley Orgánica de Educación (n. ${ }^{\circ}$ 9359). Para entonces nació el Consorcio de Colegios Católicos, integrado por la mayoría de colegios de congregaciones religiosas, en donde estarían después colegios con estructura y carácter de parroquial. 
El Consorcio nace en 1941 como una asociación sin fines de lucro, constituido por centros y programas educativos católicos que reconocen la orientación y la jerarquía eclesiástica. Sería un organismo de consulta, coordinación y apoyo para los colegios religiosos. Se relacionaría a esta institución, la Organización Internacional de la Enseñanza Católica, La Confederación Interamericana de Educación Católica, La Comisión Episcopal de Educación de la Confederación de Obispados del Perú, Las oficinas de Educación Católicas de las Diócesis, entre otros. Entre sus servicios se anotó capacitar a docentes y administrativos de los centros, asesorar a través de un equipo en aspectos de pedagogía, lo legal y lo contable; establecer misiones educativas y pastorales para compartir experiencias y aportar material educativo para el apoyo en el dictado de clases.

El 19 de diciembre de 1945, en el local de la Recoleta en Lima, se reúnen agrupaciones de los Colegios Religiosos, casi todos formados por los colegios de primera categoría. El objetivo sería establecer la Asociación de Padres de Familia de Colegios Católicos, según consta en el boletín n. 5 del Consorcio. Aquí no se especifica la delegación de algún plantel parroquial.

Dos hechos, entre 1950 y 1960, tendrían trascendencia en las esuelas parroquiales. Se trata del desarrollo de un modelo de parroquia con claras influencias anglosajonas. El colegio parroquial de influencia española colonial sufre cambios. La explicación de este cambio la mencionamos porque nos parece de gran importancia para el presente trabajo uno es la llegada de los Maryknoll en 1943 y la otra la de los Columbanos en 1952.

Los Maryknoll llegaron al Perú en el año 1911. Primero lo hicieron para desempeñar su labor misionera en el Altiplano, luego se establecieron en Lima en 1945 con una casa de encuentros. Desde 1950, con la ayuda de María Rosario Araos, fundaron la Parroquia de Santa Rosa en Lince, en la cual incorporaron como labor parroquial un colegio que con el tiempo se 
convirtió en modelo de los colegios parroquiales en el Perú. Casualmente su Párroco Juan Lawler hizo que el centro educativo fuera una comunidad de solidaridad entre laicos, padres de familia, profesores y alumnos. Esta labor de los Maryknoll fue tan importante que se extendió a la creación de otros centros como Nuestra Señora de Guadalupe en la Victoria y Niño Jesús en Ciudad de Dios. De este modo, se extendió el trabajo apostólico hacia las barriadas de la capital. El sistema organizativo de las Parroquias regentadas por los Marynoll sirvió de modelo para dar ayuda a los fieles: en lo económico con una Cooperativa de Crédito; en el servicio de salud, con un Centro Médico, y una excelente educación con la escuela parroquial, modelo que muchas parroquias todavía mantienen.

Los sacerdotes de la sociedad misionera de San Columbano, aunque de fundación irlandesa, sacerdotes que llegaron al Perú de Australia, Nueva Zelanda y Estados Unidos. Llegaron en 1951 invitados por el obispado limeño. Se ubicaron en el Cono Norte de la capital donde actualmente se encuentran los distritos de San Martín de Porres, Comas, Independencia, Los Olivos y Puente Piedra. Fueron los testigos de la formación de las zonas marginadas con sus barriadas e invasiones. Llegaron a establecer en dicho territorio, hacia la década del 60, tres colegios parroquiales de secundaria y cincuenta y dos colegios para primaria (cf. Klaiber 1988: 365). Igual que los Maryknoll, influyeron en el cambio de la escuela parroquial venida desde la época colonial. Establecieron la parroquia autosuficiente, sostenida por la labor de sus fieles, los cuales eran también usuarios del colegio parroquial. Sus quermeses, bingos y donaciones, favorecieron la ampliación de sus locales y el mejoramiento del sistema educativo. 
5. 6. Modelos de escuelas parroquiales: Santa Rosa de Lima, Fe y Alegría y El Buen Pastor

Vamos a describir los siguientes casos como ejemplo del trabajo realizado por las instituciones dirigidas por las parroquias.

a) Santa Rosa Maryknoll.

En agosto de 1947, cuando en el barrio de Lobatón (Lince-Lima) tenían fieles católicos, pero que casi no tenían practicas religiosas, algunas gestiones vecinales, encabezadas por Rosa Araos, permitió la celebración de misa los domingos en el patio de la Escuela Japonesa, situada en la cuadra 4 del Jr. León Velarde. Al verse que semanalmente acudían más de quinientas personas, el Cardenal Guevara, comisionó al Padre Bonner, provincial Meryknoll, para que se estableciera una Parroquia en la urbanización Risso. La señorita Araos al principio cedió su casa como local de la Parroquia, hasta que la urbanizadora Risso donó los siete mil metros cuadrados en el cual se estableció el nuevo local parroquial. Monseñor Lane, superior general de la Sociedad Maryknoll, dispuso que fuera el primer párroco al Padre John Lawler. ${ }^{3}$

Su llegada al Perú fue para desempeñar labores de apostolado en el altiplano boliviano. El 20 de noviembre de 1950 es nombrado Párroco de Santa Rosa y comienza su labor digna de elogio. Con su tutela se dio inicio a las obras parroquiales cuyos resultados fueron el colegio, el templo (como centro de servicios sociales), la casa cural y el convento para religiosos. Su labor trascendió hasta ser reconocido por el Consejo del Distrito de Lince

3 El Padre Lawler había nacido, en 1915, en Preston (Inglaterra). Su ordenación se había realizado el 21 de junio de 1942. 
en 1956 y ser el partícipe de un Reglamento para Planteles Parroquiales, el primero que estableció el Ministerio de Educación (1965).

El colegio parroquial se estableció el 2 de setiembre de 1951 como Escuela Parroquial (al costado del templo parroquial, entre las calles Francisco de Zela y Almirante Guisse, en la Urbanización Risso). Inició sus clases en abril de 1952 con 4 aulas y 100 alumnos. En 1957, pasa a categoría de Colegio con capacidad para enseñar la Educación Secundaria. El Párroco se convirtió en el Director y su organización después influyó en otros colegios del país.

El colegio fue trabajado desde la formación pedagógica hasta la formación cívica y religiosa del educando. Su participación en el auto gobierno y el desempeño de responsabilidades favoreció una formación más participativa. Los padres de familia, fieles de la parroquia, se convirtieron en colaboradores de la formación de sus hijos, su participación llegó a convertirlos en miembros de la cooperativa de crédito y activos concurrentes en los movimientos de seglares que se daban en la parroquia. El sentido comunitario y participativo de parte de los religiosos, alumnos y padres favoreció a un mejor desempeño del trabajo parroquial que ayudó a la formación de una comunidad cristiana muy sólida, en la cual la escuela parroquial era un elemento principal.

b) Fe y Alegría

Surge en el barrio de Latia, en Caracas (Venezuela) en 1955, con la tutela del sacerdote chileno José María Velaz. Comenzó, en un barrio para pobres, como un trabajo de apostolado de jóvenes universitarios en obras sociales. Un albañil de esos lugares donó su casa para trasformar la labor social en 
escuela. Su expresión como movimiento decía «fe en Dios, fe en el hombre, obra privilegiada de Dios, fe en nuestro siglo, fe en nuestra cultura y en el progreso como impulso de Dios en la historia y alegría de poder vivir realmente esta fe, de poder conocer el camino libre y luminoso a tantos niños, jóvenes y hombres tristes amarrados hoy a una ignorancia miserable» (cf. Reátegui 1970).

En el Perú, la primera escuela fue construida en Valdivieso, en el distrito de San Martín de Porres, y el primer rector fue el padre Antonio Durán (1965). Al siguiente año, se abrieron nuevas escuelas en Pamplona, Condevilla Señor y Chacarilla Otero. La ampliación de nuevos locales se hizo en provincias que comenzaron en Piura y fueron más amplias en la zona del terremoto del 31 de mayo de 1970 (Ancash-Huaraz).

Las escuelas tuvieron el carácter de parroquial. Algunas de ellas estuvieron adjuntas al local de la Iglesia, con clara influencia del párroco, en otras no había ejercicio de su autoridad porque se entregaba la administración a una congregación religiosa.

"Fe y Alegría» se convirtió en un movimiento de educación popular que se sustenta en ayuda de la colectividad y parte del estado. Se hizo importante para su sostenimiento las telemaratones que se hacían y la rifa anual todavía existente. El trabajo de sus servicios ha sido siempre tan efectivo que ha contribuido para que recibieran la filantropía de los medios de difusión, las donaciones de industriales y la colaboración del público en general .

La labor educativa es tan significativa que en pueblos jóvenes es el símbolo de una educación gratuita o cómoda, enseñanza integral que muestra una iglesia humana y comprometida. 
c) El Colegio Diocesano «El Buen Pastor»

La historia de la «Escuela Parroquial Sol de Oro», como se llamó a esta institución educativa del Cono Norte de Lima y hoy se llama «El Buen Pastor», está ligada a los padres irlandeses de San Columbano. Esta congregación llegó al Perú en 1952. El Padre Miguel Fitzgerald fue uno de los pioneros que estableció las parroquias en zonas «27 de Octubre» (hoy Distrito de San Martín de Porres) y desde allí creció la labor catequética hasta establecer 26 parroquias a fines de la década del 90. Una de ellas, en la Urbanización en Sol de Oro, fue la parroquia El Buen Pastor.

En 1965, de acuerdo a la Resolución Directoral n. 10032 del 26 de julio, se estableció la Escuela Parroquial Mixta Sol de Oro. Fue su primer director el padre Owen O'Kane, párroco de la parroquia El Buen Pastor. Desde ese momento el centro educativo creció hasta transformarse en colegio parroquial con niveles primario y secundario.

En 1969, un nuevo impulso con el párroco Leo Grant favorece cambios tanto en el local como en su sistema educativo hasta convertirse en líder de los colegios parroquiales de su zona. En 1992, cuando la parroquia El Buen Pastor pasa la dirección de los padres españoles Rafael Navarro y luego Pedro Martínez, la institución se convierte en una institución modelo, tanto en infraestructura como en el manejo de un gran proyecto educativo que comprendió mejoras en capacitación docente, planes de estudio, renovación completa de laboratorios, apertura de nuevos locales, especialmente para cada uno de los niveles y hasta viviendas para sus docentes.

El nombre para entonces pasaría de Escuela Parroquial Sol de Oro a Colegio Parroquial Diocesano «El Buen Pastor». Sus actividades extra programáticas se proyectarían a la comunidad con un Festival Internacional de Danza que se da anualmente y el modelo de desarrollo institucional 
como ejemplo para otras instituciones educativas parroquiales del sector. Este colegio parroquial ha seguido manteniendo su liderazgo y es el ejemplo vivo de la forma cómo la iglesia puede manejar su labor educativa más allá de los parámetros escolarizados.

\subsection{La escuela parroquial en las últimas décadas}

Toda la década del 60, con los gobiernos de arquitecto Belaunde y parte el Gobierno Militar de la Fuerza Armada, la cooperación Estado-Iglesia fue muy bien canalizada por la Oficina Nacional de Educación Católica (ONDEC), la cual tenía su oficina en el mismo edificio del Ministerio de Educación. El inicio de las reformas de Estado a partir de 1969, y la reforma educativa de 1972, politizó los cambios educativos. La discusión del tema educativo polarizó entre defensores del régimen militar y sus retractores. La preocupación por los cambios llevó para que la Iglesia expectante hiciera que participaran religiosos como colaboradores técnicos del cambio. Personajes como el padre Ricardo Morales, la hermana Shona García y el hermano Julio Corazao son ejemplos de educadores que buscaban salvaguardar la libertad de la educación y la enseñanza religiosa, frente a algunos asesores de clara tendencia agnóstica y marxista. Sin embargo, se quiso desconocer la cooperación del Estado en los centros que impartían la educación católica como los colegios parroquiales y los centros escolares de Fe y Alegría. Por esta razón, el episcopado tuvo que protestar junto con el Consorcio de Colegios Católicos.

Las Conferencias del Episcopado Latinoamericano, como la de Medellín, trajeron mucho entusiasmo entre los católicos. Pudo marcar una época de influencia para los Colegios Parroquiales. Aparecieron grupos intelectuales que apoyaron la educación de los pobres con los 
cuales la iglesia se tenía que identificar. La Reforma Educativa polarizó a progresistas y conservadores en la educación popular, a los cuales la iglesia católica situó en las instituciones de dirección parroquial. Esta influencia llegó hasta las instituciones como el Consorcio de Colegios Católicos y la ONDEC, esta última que representaba a los colegios católicos de la clase media y popular.

La Reforma Educativa convirtió la educación en problemática de cuestión política, social y económica. El magisterio se politizó formando el SUTEP (Sindicato Único de Trabajadores en la Educación). La educación privada quedó sujeta a un rígido control y las regulaciones estatales. Las escuelas parroquiales todavía resistieron las «concesiones» y llegaron a 1980 para ver cambios que anularon muchas de las propuestas de la reforma.

La nueva ley general de Educación de 1982, con algunas cambios estructurales, casi no tocó a las Escuelas y Colegios Parroquiales, los cuales siguieron permaneciendo, en muchos aspectos, casi como lo había establecido el Reglamento respectivo de 1965: nombramiento de profesores, cooperación de iglesia — estado, administración de los párrocos, etc.

El gobierno de la década del 90, sus retos educativos al principio estuvieron en la construcción de locales antes que en el cambio de estructuras educativas. Instituciones internacionales como el FMI (Fondo Monetario Internacional), BM (Banco Mundial) y BID (Banco Interamericano de Desarrollo) determinaron el modelo educativo con el condicionante de préstamos y ayuda económica. Labores como el reparto de alimentos, el seguro escolar, el reparto de textos, la instalación de computadoras y la capacitación masiva de profesores, fueron la justificación de la inversión en educación.

Vencido el terrorismo, el régimen favoreció la expansión de la educación privada en todos los niveles. Las instituciones educativas se vieron 
como empresas lucrativas, de negocios lícitos de ganancia que tendrían que pagar impuestos. Estas preventivas se especificaron en la Ley 882, de fomento de la educación particular. Las escuelas parroquiales muchas se han acogido a ella, mientras que otras permanecen fieles a su sistema de cooperación Iglesia-Estado, pero con la preocupación de haber perdido su sentido comunitario.

\section{LAS ESCUELAS Y COLEGIOS PARROQUIALES EN PERSPECTIVA}

Una explicación del reglamento que estableció la presencia de los colegios parroquiales en la educación peruana

En los primeros meses de 1965, a propuesta del Estado, se estableció en el Ministerio de Educación una Comisión Presidida por Luis Cabello Hurtado (lo acompañaron Abelardo Murillo y el padre Juan Lawler), con el fin de crear un Reglamento que solucione las interrogantes sobre la relación entre la Iglesia y el Estado, con respecto a los llamados Planteles Parroquiales. El reglamento fue redactado el 2 de julio y establecido por Decreto Supremo n. ${ }^{\circ} 45$ del 6 de julio de 1965 y se amplió con el Decreto Supremo n. ${ }^{\circ} 48$ con fecha del 27 de julio del mismo año. En el reglamento se pudo distinguir dos partes: la primera, que caracteriza a los Planteles Parroquiales, especificando los fines que perseguía; en la segunda se precisaron las relaciones entre la Iglesia y el Estado, en lo que se refería sobre los nombramientos al personal, constituciones y subvenciones especiales. Existe una parte ampliatoria que complementa la segunda parte.

La primera parte comenzaba haciendo una justificación legal de los colegios parroquiales dentro del sistema educativo. Sobre todo con el capítulo XIV de la Constitución y la Ley orgánica de la educación pública 
n. ${ }^{\circ}$ 9359. Se determinó que incluía a los planteles educativos particulares sostenidos por las órdenes y congregaciones religiosas. Tenían carácter de gratuitos, por el apoyo que el Estado les daba, o cobraban pensiones muy cómodas. Por ello, acogió a algunos colegios de la iglesia de categoría popular. Luego ingresó de lleno a la caracterización de dichos planteles educativos. Allí se menciona que son centros educativos zonales, a los que se les da preferencia para aceptar en sus aulas a los hijos de los parroquianos que viven en la jurisdicción de la parroquia, y se indica quienes tendrán la oportunidad de dirigirlos, sin llegar a especificar la proporción de las personas nacionales, extranjeros, religiosos o seglares. Pero es confuso con respecto a los profesores o los trabajadores; sin embargo, en cuanto al uso del local fueron detallistas(desde el artículo 7 al 10). En todos ellos se trata claramente del mantenimiento, la construcción y arriendo.

La segunda parte comprende lo relacionado con las pensiones. Sin explicar razones de su cobros, se categorizó dentro de la clase «C» las bajas pensiones, lo cual diferenciaba de los pagos que hacían los alumnos de los llamados colegios «A», en los cuales se educaban los hijos de las personas de clase media y alta, estaba principalmente en barrios residenciales. Esta clase de pensiones "C» fueron más bajas en los colegios parroquiales de provincias, en donde se llegó, en algunos casos, a pedir apenas el $40 \%$ de aquello que mandaba el reglamento. El documento escueto en su reglamentación y casi de corte simplista, favoreció para que muchos colegios religiosos tuvieran profesores nombrados con rentas del estado o llegaran a recibir prebendas que se les daban a los colegios parroquiales. Por eso cuando llegó el momento de la Reforma Educativa de 1972, el estado quitó la ayuda a muchas escuelas religiosas y algunas parroquiales, confundiendo su origen, capacidad social y mérito que pudo tener el sistema dentro de la educación peruana. 


\section{Situación de la escuela parroquial en el Perú}

La escuela parroquial, como se ha visto, ocupó siempre un sitio dentro de la Iglesia y del Estado. Su espacio dentro de la Parroquia y el Distrito, favoreció el juego de potencialidades cuya importancia no se ha sabido aprovechar en la educación peruana. En la colonia, fue el colegio elemental que no se llegó a extender en un régimen de estructuras sociales y económicas muy marcadas, pero sirvió para que muchas personas de bajos recursos llegaran a formarse con la nueva cultura. En la emancipación y los primeros años de la República sirvió de apoyo a la formación de la educación básica elemental y primaria que reglamentaron los gobiernos republicanos. En el siglo xx, se convirtió en un modo de extender la educación al pueblo en forma masiva, pero no como se estaba acostumbrado en el sistema educativo, con privaciones y deficiencias, sino de una manera más comunitaria, organizativa, y sobre todo, basado en una elevada calidad de la educación, a bajo costo para los padres de familia y el Estado. Es y ha sido una de las pocas instituciones que, por su influencia social y religiosa, ha seguido conviviendo en nuestra educación peruana, a pesar de cambios, intentos de mejoría y circunstancias de renovación. Podemos decir, sin llegar a equivocarnos, que la Escuela Parroquial representa para el estado:

- Un medio que puede darle sentido de comunidad y cooperación al grupo social de un barrio o un pueblo (en el caso de provincias). Une a las familias de distintas clases, se encaran problemas de la comunidad y a través de las parroquias hay una labor gregaria de ayuda.

- Se puede aprovechar los recursos humanos en la comunidad, conjuntamente con instituciones como los Municipios, Clubes sociales y culturales. No olvidemos que la Parroquia representó 
en nuestra historia otra institución del Estado y el Párroco, el organizador de recursos que ayudó al Alcalde y al Gobernador en el pueblo de provincia.

- En los primeros años la Parroquia sirvió al estado en la educación pública, ella contrarrestó el agobiante centralismo. Ahora los gobiernos regionales pueden utilizarlos para el desarrollo de aldeas y pueblos.

- Después de la Familia viene la Parroquia. No podemos negar que hacia la familia, célula y base del Estado, van dirigidos los esfuerzo para el progreso del país. Pero ¿qué viene después de ella? Sin duda la parroquia. Ella cuida la base espiritual, fuente del mantenimiento de la estructura de las sociedades.

Para la Iglesia la escuela parroquial siempre ha significado:

- La forma directa de llegar a los fieles y poderlos catequizar y evangelizar, sobre todo, ahora que se habla del «apostolado de los laicos», cuya labor ha tomado una importancia en la labor que realiza la Iglesia. La escuela parroquial es el mayor ejemplo de esa labor. Ya se ha visto sus frutos en grupos como Escuela de Padres, Confirmaciones, Primera Comunión, Encuentros matrimoniales, entre otros.

- La escuela de la parroquia ha representado la mejor la ayuda que el Estado ha podido prestar a la Iglesia. El impacto de la educación para el pueblo se clarificó mostrándose calidad, organización, eficacia y responsabilidad. La iglesia en esta clase de instituciones ha mostrado, con la calidad que imparte, que los pobres también tienen el derecho a tener la educación que está reservada para las clases económicamente privilegiadas. 
- La iglesia comprometida con los pobres, tiene en la escuela parroquial el ejemplo para la formación de sus parroquianos. Así surgió en la colonia, así permaneció en la República. Muchos hemos visto la labor de la parroquia con su escuela en provincias y los centros de Fe y Alegría en las zonas periféricas urbanas. En todas ellas, la educación religiosa ha significado la formación de los fieles y la labor de los religiosos junto con los seglares en las cosas de la fe. 


\section{BIBLIOGRAFÍA}

Actas del Primer Congreso de Historia Eclesiástica

1990 La evangelización del Perí en los siglos XV-XVII. Arequipa: s.e.

BASADRE, Jorge

1969 Historia de la república del Perú. Tomo II y IV. Lima: Universitaria.

Birgillist. $M$.

1921 Derechos y deberes de los párrocos y sus vicarías. Barcelona: Liturgia.

CARDó Franco, Andrés

s.f. "La iglesia y la educación peruana en el siglo XX». Revista de Historia Eclesiástica, n. ${ }^{\circ}$ 6. Academia Peruana de Historia Eclesiástica.

Donos, Justo

1869 Manual de párroco americano. París: s.e.

Dulanto, Juan

1963 La educación en la historia constitucional del Perú. Lima: Max Cárdenas.

GALDO, Virgilio

s. f. "Colegio de Curas: frente a dos mundos». Revista Educación, n. ${ }^{\circ} 3$. Lima.

GonZÁLES, Paula (ed.)

1858 El constitucional. Periódico Semanal. Lima: Vigil.

Huerta, José (ed.)

1855 El católico: periódico religioso, filosófico, histórico y literario. Lima. s. e. 
JORDAN, Jesús

1950 Pueblos y parroquias del Perú. Tomo I. Lima: s.e.

KLAibER, Jeffrey S. J.

1988 La iglesia en el Perí. Lima: PUCP.

LUZURIAGA, Lorenzo

1961 Historia de la educación y la pedagogía. Buenos Aires: Lozada.

MacLean, Roberto

1950 Sociología de la educación educativa. Lima: s.e.

Ministerio de EduCACión

1977 Reglamento de centros educativos parroquiales. Lima: Ministerio de Educación.

Nieto Vélez, Armando S. J.

1992 Francisco del Castillo: el apóstol de Lima. Lima: PUCP.

Oficina Nacional de Educación Católica(ONDEC)

s. f. Centros educacionales dirigidos por religioso: estudio de su distribución por diócesis. Lima: ONDEC.

PONCE, Jaime y Daniel RoACH

1968 Los Maryknoll en el Perú: estudio de opiniones y actitudes. La Paz: s.e.

ReÁtegui Guzmán, Gladys

1970 Fe y Alegría, por una educación popular integral. Tesis PUCP. 
RedDum, Ryan

1955 Filosofía católica de la educación. Madrid: Morante.

UnIVERSIDAD DEL PACÍfICO

1980 Independencia, iglesia y clase popular. Lima: UP.

VARGAS UGARTE, Rubén S. J.

1953 Historia de la Iglesia Católica. Tomo I. Lima: Santa María. 